Research Paper

\title{
Possible association of arrestin domain-containing protein 3 and progression of non-alcoholic fatty liver disease
}

\author{
Masahiro Ogawa\#, Tatsuo Kanda\#, $₫$, Teruhisa Higuchi, Hiroshi Takahashi, Tomohiro Kaneko, Naoki \\ Matsumoto, Kazushige Nirei, Hiroaki Yamagami, Shunichi Matsuoka, Kazumichi Kuroda, Mitsuhiko \\ Moriyama \\ Division of Gastroenterology and Hepatology, Department of Medicine, Nihon University School of Medicine, 30-1 Oyaguchi-kamicho, Itabashi-ku, Tokyo \\ 173-8610, Japan \\ \#These authors equally contributed. \\ $\triangle$ Corresponding author: Tatsuo Kanda, M.D., Ph.D., Associate Professor, Division of Gastroenterology and Hepatology, Department of Medicine, Nihon \\ University School of Medicine, 30-1 Oyaguchi-kamicho, Itabashi-ku, Tokyo 173-8610, Japan. E-mail: kanda.tatsuo@nihon-u.ac.jp; Phone: +81-3-3972-8111; Fax: \\ $+81-3-3956-8496$ \\ (c) Ivyspring International Publisher. This is an open access article distributed under the terms of the Creative Commons Attribution (CC BY-NC) license \\ (https://creativecommons.org/licenses/by-nc/4.0/). See http://ivyspring.com/terms for full terms and conditions.
}

Received: 2019.02.19; Accepted: 2019.05.03; Published: 2019.06.02

\begin{abstract}
The prevalence of non-alcoholic fatty liver disease (NAFLD) and non-alcoholic steatohepatitis (NASH) is increasing worldwide. Several effective drugs for these diseases are now in development and under clinical trials. It is important to reveal the mechanism of the development of NAFLD and NASH. We investigated the role of arrestin domain-containing protein 3 (ARRDC3), which is linked to obesity in men and regulates body mass, adiposity and energy expenditure, in the progression of NAFLD and NASH. We performed knockdown of endogenous ARRDC3 in human hepatocytes and examined the inflammasome-associated gene expression by real-time PCR-based array. We also examined the effect of conditioned medium from endogenous ARRDC3-knockdown-hepatocytes on the apoptosis of hepatic stellate cells. We observed that free acids enhanced the expression of ARRDC3 in hepatocytes. Knockdown of ARRDC3 could lead to the inhibition of inflammasome-associated gene expression in hepatocytes. We also observed that conditioned medium from endogenous ARRDC3-knockdown-hepatocytes enhances the apoptosis of hepatic stellate cells. ARRDC 3 has a role in the progression of NAFLD and NASH and is one of the targets for the development of the effective treatment of NAFLD and NASH.
\end{abstract}

Key words: ARRDC3; Hepatic Stellate Cells; Inflammasome; NASH; Steatosis

\section{Introduction}

The diagnosis rate of nonalcoholic fatty liver disease (NAFLD), including nonalcoholic steatohepatitis (NASH), continues to increase in Western and Eastern countries [1,2]. Fatty liver diseases are growing causes of cirrhosis and hepatocellular carcinoma (HCC) globally [3]. Although it has been reported that various factors are involved in the mechanism of the development of NAFLD and NASH [4], the exact mechanism is still unknown. It is important to elucidate the mechanism of the progression of NAFLD and NASH.
It has been reported that $\beta$-arrestins play an important role in metabolism $[5,6]$. $\beta$-arrestins have been discovered as molecules that bind to and desensitize the activated and phosphorylated form of the $G$ protein-coupled $\beta 2$-adrenergic receptor [5]. Loss or dysfunction of $\beta$-arrestin-2 leads to the disturbance of insulin signaling [6]. $\beta 2$-adrenergic receptor activation could control the antiapoptotic effects of the $27-\mathrm{kDa}$ heat shock protein (HSP27) through association with $\beta$-arrestin [7]. $\beta$-arrestin dimerization regulates $\beta 2$-adrenergic receptor-mitogen activated 
protein kinase (MAPK) signaling, cell death and proliferation $[8,9]$. The effects of the $\beta 2$-agonists via $\beta 2$-adrenergic receptors increase cAMP and interfere with gene expression of peroxisome proliferator-activated receptors (PPARs), which are transcription factors belonging to the nuclear receptor superfamily [10]. Knockdown of $\beta$-arrestin-2 also prevented the cAMP-binding protein Epac1-induced histone deacetylase 4 (HDAC4) nuclear export [11]. $\beta 2$-adrenergic receptor agonists may possibly exert multiple effects including a direct-effect on liver $\beta 2$-adrenergic receptors and could promote recovery from insulin-induced hypoglycemia [12].

$\beta$-arrestin-2 binds apoptosis signaling-regulating kinase 1 (ASK1), mitogen-activated protein kinase kinase 4 (MKK4), and mitogen-activated protein kinase 10 (JNK3) and promotes JNK3 activation [13]. The activation of ASK1 in hepatocytes is a key step in the progression of NASH $[4,14]$.

The a-arrestins are broadly expressed and include 6 mammalian members referred to as arrestin domain-containing proteins (ARRDCs) [15]. The a-arrestins also have a similar structure to $\beta$-arrestins, and these play roles in $G$ protein-coupled receptor trafficking [15]. The a-arrestin family includes thioredoxin-interacting protein (Txnip) which has crucial functions in regulating glucose uptake and glycolytic flux through the mitochondria [16], and arrestin domain-containing protein 3 (ARRDC3), which is linked to obesity in men and regulates body mass, adiposity, and energy expenditure [16, 17]. ARRDC3 is localized in the cytoplasm and expressed in the liver.

A genome-wide association study (GWAS) identified a single nucleotide polymorphism (SNP) upstream of the ARRDC3 locus strongly associated with prognosis in early-onset breast cancer [18]. Genome-wide association analysis in East Asians also identified an SNP near the ARRDC3 gene associated with breast cancer risk [19].

In the present study, we observed the enhancement of ARRDC3 expression by the addition of oleic acids in human hepatoma cells. We have also used the siRNA targeting ARRDC3 to inhibit the expression of endogenous ARRDC3 in human hepatoma HepG2 cells and determined its effect on inflammasome pathway-associated gene expression. Furthermore, we treated human hepatic stellate cell line LX-2 with conditioned media from HepG2 cells transfected with or without ARRDC3-targeted siRNA and evaluated apoptosis of hepatic stellate cells. We have observed that the depletion of ARRDC3 in human hepatocytes resulted in the downregulation of inflammasome pathway-associated genes such as chemokine (C-X-C motief) ligand 2 (CXCL2), interleukin 6 (IL6), chemokine (C-C motief) ligand 5 (CCL5), caspase 5 (CASP5) and interferon, beta 1 (IFNB), and the enhancement of apoptosis of hepatic stellate cells treated with their conditioned media. Our results demonstrated ARRDC 3 may play a role in the development of NAFLD and NASH.

\section{Results and Discussion}

\section{Human hepatocytes express ARRDC3 mRNA.}

We previously observed that ARRDC3 mRNA was significantly higher expressed in the liver of NASH model rat SHRSP5/Dmcr [20] at week 4 after feeding a normal diet compared with those of the stroke-prone spontaneously hypertensive rat (SHRSP/Izm) (data not shown). SHRSP5/Dmcr or SHRSP/Izm, respectively, develops or not develops NASH at week 19 after feeding a high fat, high cholesterol-containing diet. Previous studies have demonstrated that various human cell lines express ARRDC3 [17, 21].

First, we examined ARRDC3 mRNA expression in the human hepatoma cell lines, HepG2 and Huh7, compared with that in human pancreatic cancer cell line MIAPaCa-2. Cellular RNA was extracted from these cell lines, and ARRDC3 mRNA levels were examined by real-time RT-PCR (Figure 1). We observed that human hepatocytes express ARRDC3 mRNA significantly higher than human pancreatic cancer cells.

Hoque et al. [22] reported that lactate negatively regulates toll-like receptor (TLR) induction of Nucleotide-binding oligomerisation domain (NOD)-like receptor protein 3 (NLRP3) inflammasome and production of interleukin $1 \beta$ (IL1 $\beta)$, via $\beta 2$-arrestin and the plasma membrane Gi protein coupled receptor (GPR)-81 and reduces organ injury in liver and pancreas. So, we also used human pancreatic cancer cells. As oleic acid induced steatosis and cytotoxicity on rat hepatocytes in primary culture [23], we did not use human primary hepatocytes in the present study.

\section{Oleic acids enhance ARRDC3 mRNA expression.}

Next, we examined the effects of oleic acid, which induces steatosis in hepatocytes [24], on ARRDC3 mRNA expression in human hepatoma cell lines. We previously demonstrated that free fatty acids such as oleic acid and/or palmitic acid induced fat deposition in human hepatoma cell lines by Nile red stain [25]. We added oleic acid $(0 \mu \mathrm{M}, 150 \mu \mathrm{M}$ or $300 \mu \mathrm{M}$ ) into cell culture medium of HepG2 or Huh7 cells. Twenty-four hours after the addition of oleic acid, cellular RNA was extracted and ARRDC3 
mRNA levels were measured by real-time RT-PCR (Figure $2 \mathrm{a}$ and $2 \mathrm{~b}$ ). In both HepG2 and Huh7 cell lines, oleic acids enhanced ARRDC3 mRNA expression in a dose-dependent manner. Thus, fat deposition might be associated with ARRDC3 mRNA expression in hepatocytes.

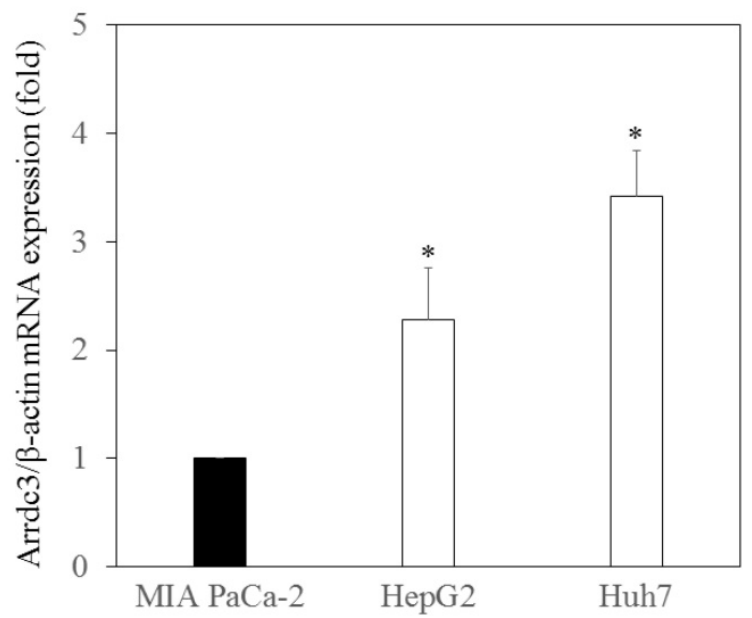

Figure 1. Arrestin domain-containing protein 3 (ARRDC3) mRNA expressed in human hepatoma cells. ARRDC3 and $\beta$-actin mRNA levels were measured by real-time RT-PCR in HepG2, Huh7 and pancreatic cancer MIAPaCa-2 cells. *p < 0.05, compared with MIA PaCa-2 cells.

$\mathbf{a}$

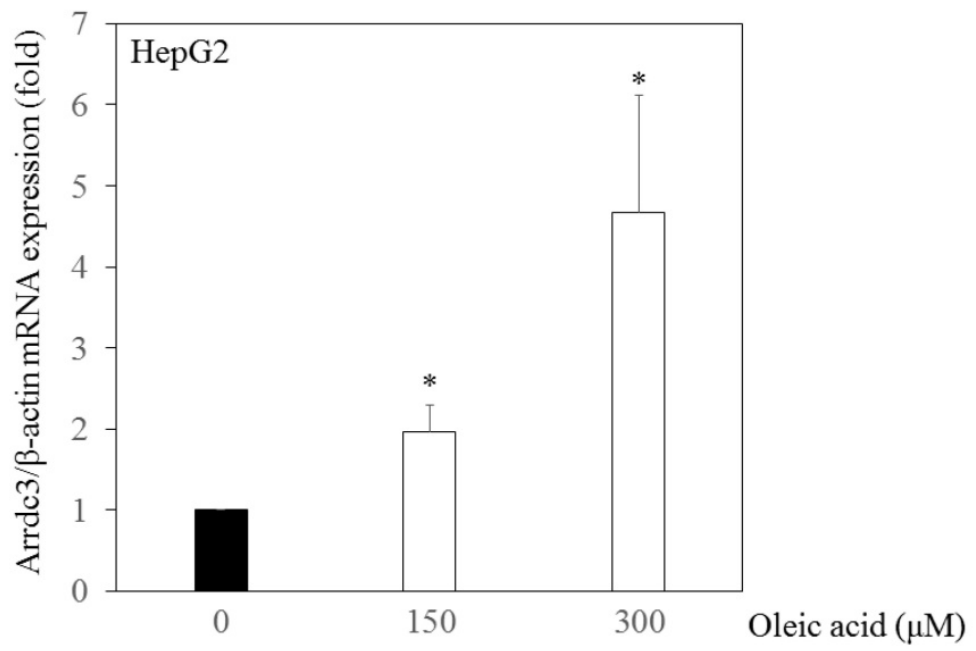

b

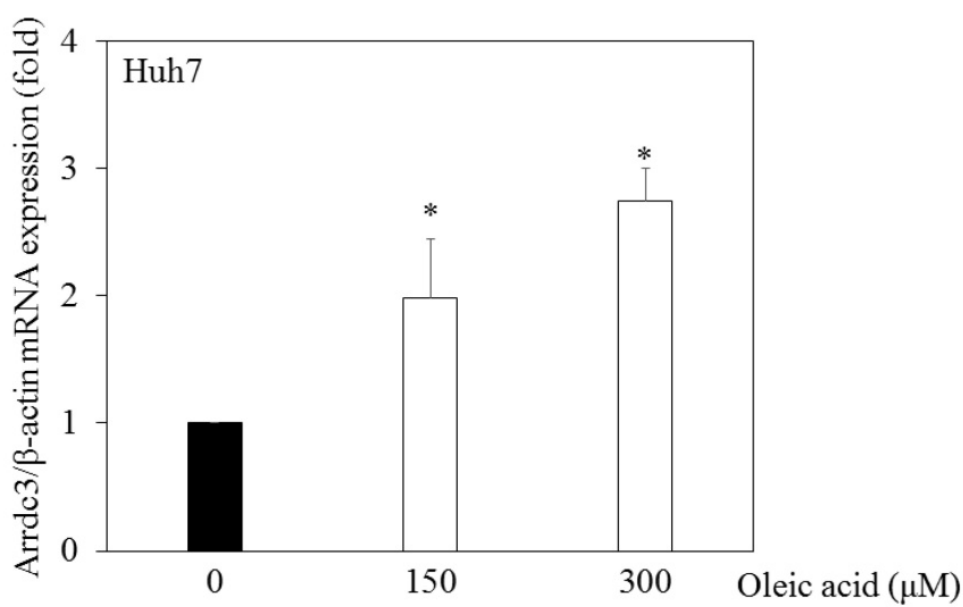

Figure 2. Effects of oleic acid on arrestin domain-containing protein 3 (ARRDC3) mRNA expression levels in human hepatoma cell lines. (a) HepG2 and (b) Huh7 cells. Real-time RT-PCR analyses of ARRDC3 and $\beta$-actin mRNA levels in HepG2 and Huh7 cells treated with or without $150 \mu M$ or $300 \mu M$ oleic acid for 24 hours. *p < 0.05 , compared with $0 \mu \mathrm{M}$ oleic acid. 
a

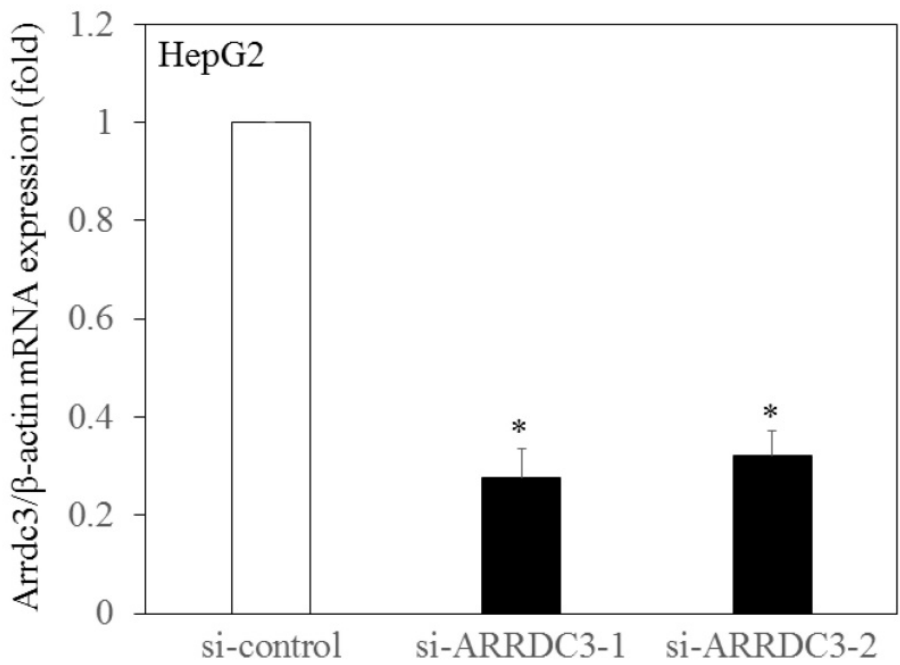

b

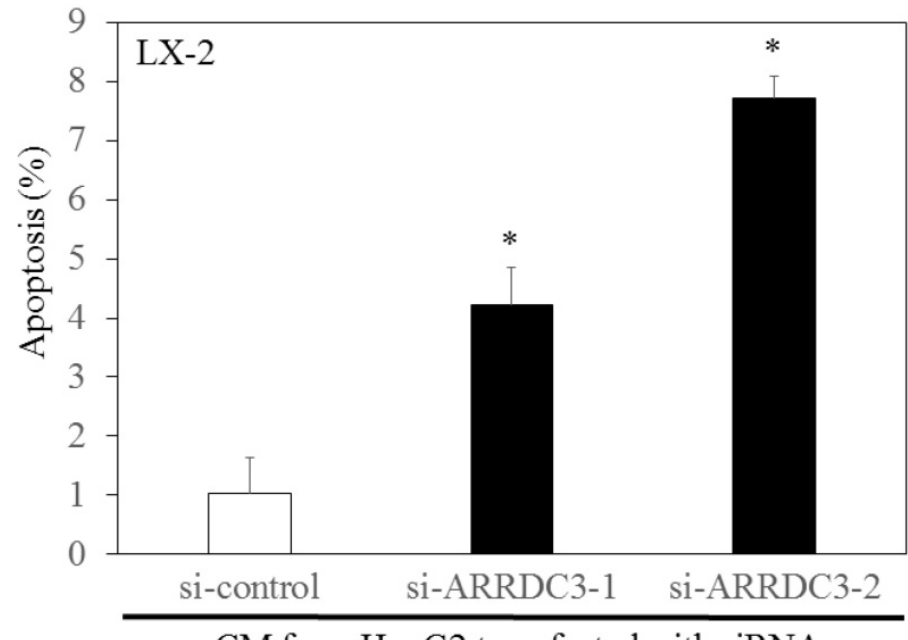

CM from HepG2 transfected with siRNA

Figure 3. Conditioned media from endogenous arrestin domain-containing protein 3 (ARRDC3)-knockdown-HepG2 enhances apoptosis of hepatic stellate cell line LX-2. (a) ARRDC3 mRNA expression was significantly inhibited by transfection with si-ARRDC3, compared with that of si-control. si-ARRDC3-1 and si-ARRDC3-2 indicate different set of experiments. (b) Conditioned media (CM) from ARRDC3-knockdown HepG2 enhanced LX-2 cell apoptosis, compared with that of control HepG2 cells. *p < 0.05, compared with control siRNA (si-control).

\section{Conditioned media from endogenous ARRDC3-knockdown-HepG2 enhances apoptosis of hepatic stellate cells.}

It is not clear whether the ARRDC3 expression in hepatocytes have any effects on human hepatic stellate cells. We investigated whether knockdown of endogenous ARRDC3 in HepG2 cells had effects on apoptosis in human hepatic stellate cell line LX-2. Forty-eight hours after transfection of siRNA into HepG2 cells, we confirmed the knockdown of ARRDC3 mRNA by real-time RT-PCR (Figure 3a). We also collected conditioned medium from HepG2 cells transfected with si-ARRDC3 or si-control, and cellular apoptosis of LX-2 cells was examined 72 hours after incubation of these media by APOPercentage apoptosis assay (Figure 3b). Cellular apoptosis of hepatic stellate cells increased after the incubation of conditioned media from ARRDC3-knockdowned HepG2 cells, compared with that from control HepG2 cells. These results suggested that upregulation of ARRDC3 in hepatocytes might inhibit hepatic stellate cell apoptosis, resulting in the progression of liver fibrosis. Although we also tried to detect apoptosis of LX-2 cells by apoptosis marker Annexin V [26], we did not see any differences more clearly (data not shown). Further studies will be needed.

\section{Knockdown of ARRDC3 inhibits inflammasome-associated gene expression in human hepatocytes.}

Inflammasomes and cytokines are major players in the induction of hepatocyte apoptosis in NAFLD and NASH [4]. To further explore the mechanism, we 
have examined inflammasome-related gene expression profiles using real-time PCR-based focused microarrays to compare between HepG2 cells transfected with si-ARRDC3 and those with siRNA. The Inflammasome-associated gene expression between HepG2 cells transfected with si-ARRDC3 and si-control were compared using inflammasomeassociated signaling target PCR array.

Out of 84 inflammasome-associated genes examined, one and 13 genes were significantly upregulated and downregulated, respectively, in HepG2 cells transfected with si-ARRDC3, compared with the si-control $(\mathrm{p}<0.05 ;$ Table 1$)$. Five genes (CCL5, CASP5, IL6, IFNB1 and CXCL2) were downregulated 3-fold or more. Heat shock protein 90 kDa alpha (cytosolic), class A member 1 (HSP90AA1) was the only gene that was significantly upregulated.

Table 1. Effects of knockdown of endogenous arrestin domain-containing protein 3 (ARRDC3) on inflammasome-associated gene expression in human HepG2 cells. Changes of gene expression in HepG2 cells transfected with si-ARRDC3, compared with si-control.

\begin{tabular}{|c|c|c|c|}
\hline $\begin{array}{l}\text { Gene } \\
\text { Symbol }\end{array}$ & Pathways & $\begin{array}{l}\text { si-ARRDC3 vs. } \\
\text { si-control }\end{array}$ & p-values \\
\hline HSP90B1 & Inflammasomes (Negative regulation) & -1.57 & 0.000089 \\
\hline BIRC3 & $\begin{array}{l}\text { Signaling Downstream of NOD-Like } \\
\text { Receptors }\end{array}$ & -1.90 & 0.0011 \\
\hline CXCL2 & $\begin{array}{l}\text { Signaling Downstream of NOD-Like } \\
\text { Receptors }\end{array}$ & -3.69 & 0.0011 \\
\hline IL6 & $\begin{array}{l}\text { Signaling Downstream of NOD-Like } \\
\text { Receptors }\end{array}$ & -6.90 & 0.0017 \\
\hline CCL5 & $\begin{array}{l}\text { Signaling Downstream of NOD-Like } \\
\text { Receptors }\end{array}$ & -10.56 & 0.0069 \\
\hline CASP1 & $\begin{array}{l}\text { Inflammasomes } \\
\text { (IPAF/NLRP1/NLRP3) }\end{array}$ & -1.51 & 0.0085 \\
\hline CASP5 & Inflammasomes (NLRP1) & -10.06 & 0.010 \\
\hline TXNIP & $\begin{array}{l}\text { Signaling Downstream of } \\
\text { Inflammasomes }\end{array}$ & -1.70 & 0.013 \\
\hline MAP3К7 & $\begin{array}{l}\text { Signaling Downstream of NOD-Like } \\
\text { Receptors }\end{array}$ & -1.30 & 0.021 \\
\hline PANX1 & $\begin{array}{l}\text { Signaling Downstream of } \\
\text { Inflammasomes }\end{array}$ & -1.22 & 0.037 \\
\hline HSP90AA1 & Inflammasomes (Negative regulation) & 1.19 & 0.039 \\
\hline PTGS2 & $\begin{array}{l}\text { Signaling Downstream of } \\
\text { Inflammasomes }\end{array}$ & -1.43 & 0.039 \\
\hline MYD88 & $\begin{array}{l}\text { Signaling Downstream of } \\
\text { Inflammasomes }\end{array}$ & -1.61 & 0.049 \\
\hline IFNB1 & $\begin{array}{l}\text { Signaling Downstream of NOD-Like } \\
\text { Receptors }\end{array}$ & -4.61 & 0.050 \\
\hline
\end{tabular}

HSP90B1, heat shock protein 90 beta family member 1; BIRC3, baculoviral IAP repeat containing 3; CXCL2, C-X-C motif chemokine ligand 2; IL6, interleukin 6; CCL5, C-C motif chemokine ligand 5; CASP1, caspase 1; CASP5, caspase 5; TXNIP, thioredoxin interacting protein; MAP3K7, mitogen-activated protein kinase kinase kinase 7; PANX1, pannexin 1; HSP90AA1, heat shock protein 90 alpha family class A member 1; PTGS2, prostaglandin-endoperoxide synthase 2; MYD88, myeloid differentiation primary response 88; IFNB1, interferon beta 1; IPAF (NLRC4), NLR family CARD domain containing 4; NLRP1, NLR family pyrin domain containing 1 ; NLRP3, NLR family pyrin domain containing 3 .

Expression levels of endoplasmic reticulum molecule Heat shock protein $90 \mathrm{kDa}$ beta (Grp94), member 1 (HSP90B1) were significantly up-regulated in the livers of zebrafish larvae fed high fat with or without high cholesterol diets [27]. Baculoviral IAP repeat containing 3 (BIRC3), a severe hypoxia-activated gene, was significantly increased in simple hepatic steatosis compared with the controls [28]. A Western-type cholesterol-containing diet significantly induced hepatic expression of CXCL2 [29]. IL6 levels were increased in NASH and correlated with GP130 expression [30]. Steatosis induced CCL5/RANTES was associated with early-stage liver fibrosis in the progression of NAFLD [31]. NLRP3 inflammasome, pro-IL1 $\beta$, active-CASP1 and IL1 $\beta$ activation occurs in NAFLD [32].

Elevation of ceramide levels was associated with activation of CASP5 and the subsequent cleavage of $\mathrm{HuR}$ and apoptotic cell death in the liver [33]. The reactive oxygen species (ROS)-thioredoxin interacting protein (TXNIP) pathway mediates hepatocellular NOD-like receptor (NLR) family pyrin domain containing 3 (NLRP3) inflammasome activation, inflammation and lipid accumulation in fructose-induced NAFLD [34]. Mitogen-activated protein kinase kinase kinase 7 (MAP3K7) induced adipocyte differentiation through peroxisome proliferator-activated receptor gamma (PPAR $\gamma$ ) signaling [35].

Pannexin 1 (PANX1)-dependent pathophysiological extracellular ATP release in lipoapoptosis is capable of stimulating migration of human monocytes in chronic liver injury induced by free fatty acids [36]. HSP90AA1 is one of the nine critical genes related to the pathogenesis of hepatocellular carcinoma [37]. Prostaglandin-endoperoxide synthase 2 (PTGS2) and myeloid differentiation primary response gene 88 (Myd88) are also associated with NAFLD and NASH [38, 39]. Mitochondrial damage in steatohepatitis extends to mitochondrial antiviral-signaling protein MAVS, an adapter of helicase receptors, resulting in inefficient type I IFN and inflammatory cytokine response [40]. Thus, it is possible that ARRDC3 might be involved in the inflammasome-associated pathways involved in the pathogenesis of NAFLD and NASH.

We performed further pathway analysis. Effects of knockdown of ARRDC3 on inflammasomeassociated pathways in human hepatocytes are shown in Figure 4. Most of inflammasome-associated genes were downregulated in HepG2 cells transfected with si-ARRDC3, compared with the si-control. However, among negative regulation molecules of inflammasomes, HSP90AA1 was significantly upregulated and B-cell CLL/lymphoma 2 (BCL2)-like 1 (BCL2L1), cathepsin B (CTSB), heat shock protein 90 $\mathrm{kDa}$ alpha, class B member 1 (HSP90AB) tended to be upregulated. 


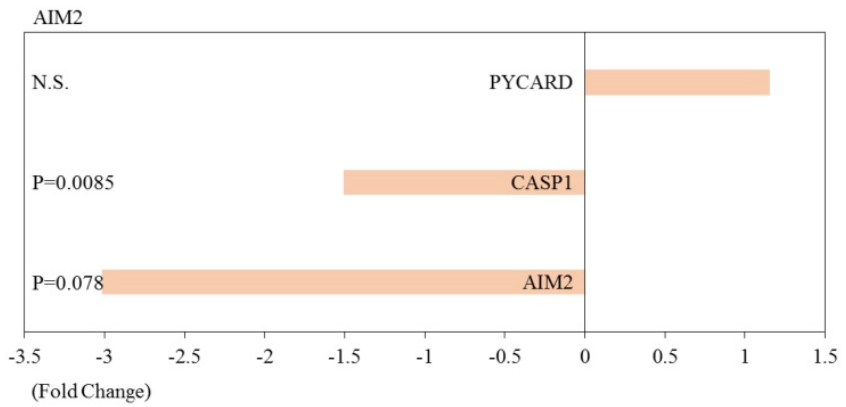

b
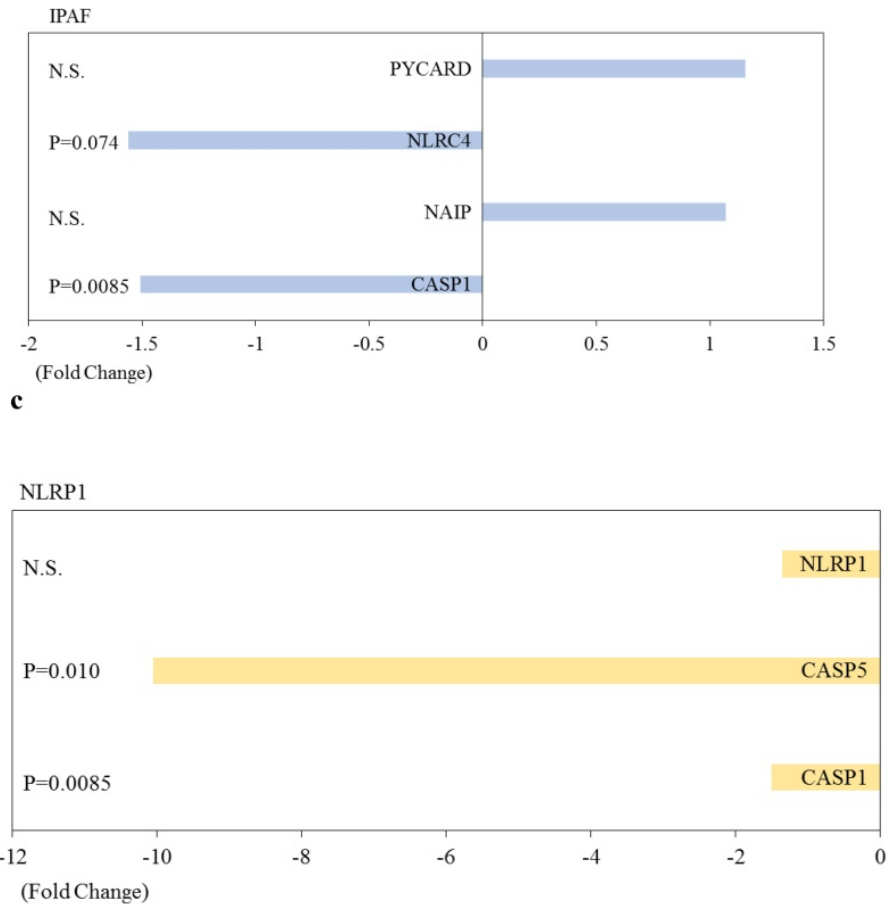

d

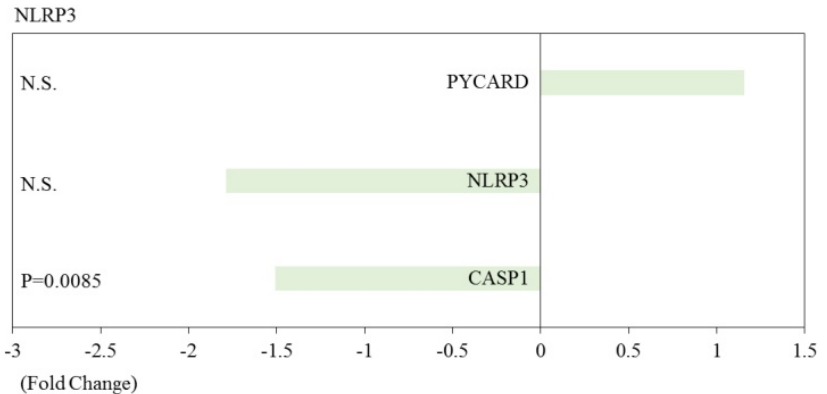


e

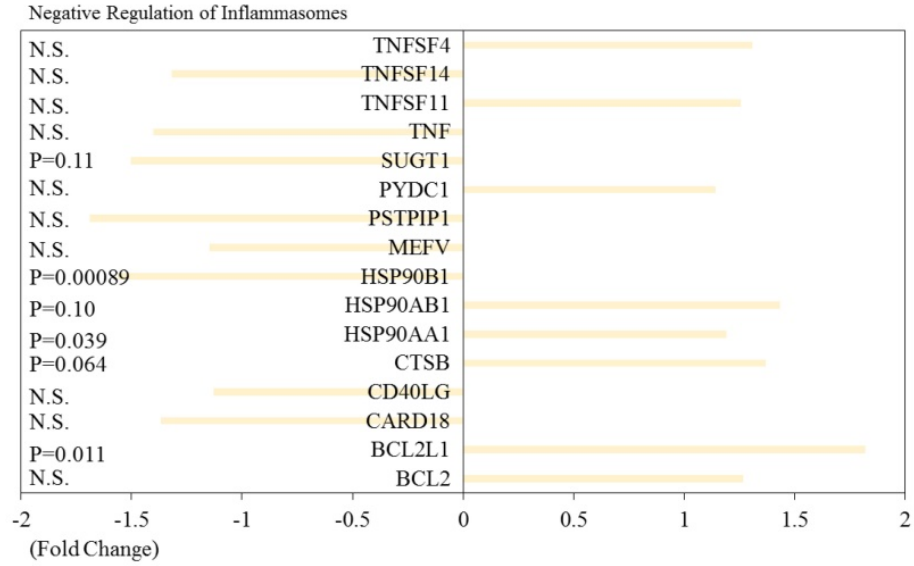

f

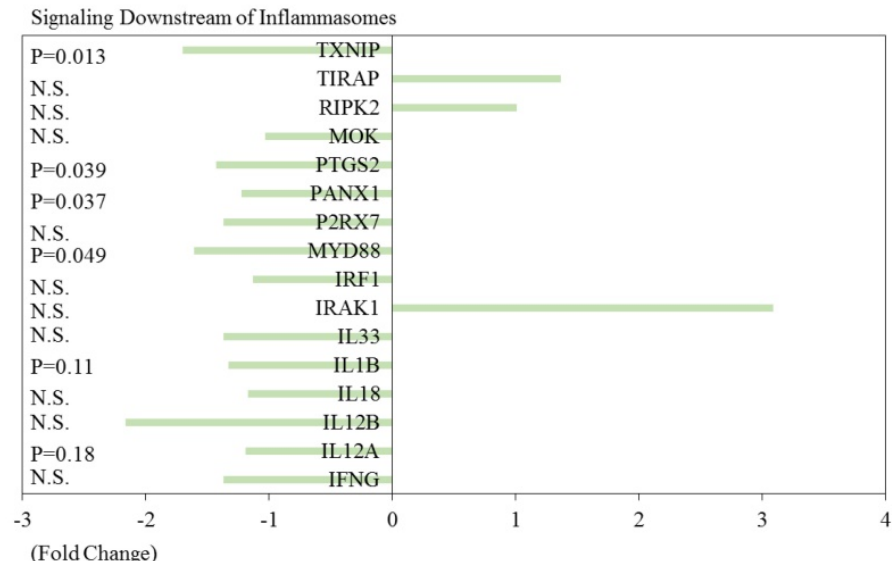

Figure 4. Effects of knockdown of endogenous arrestin domain-containing protein 3 (ARRDC3) on inflammasome-associated pathways in human HepG2 cells. Changes of gene expression in HepG2 cells transfected with si-ARRDC3, compared with si-control. (a) Absent in melanoma 2 (AIM2), (b) Ice protease-activating factor (IPAF), (c) Nucleotide-binding oligomerisation domain (NOD)-like receptor protein 1 (NLRPI), (d) NOD-like receptor family pyrin domain containing 3 (NLRP3), (e) Negative regulation of inflammasomes, (f) Signaling downstream of inflammasomes. P, p-values. N.S., not statistically significant difference.

We performed further pathway analysis. Effects of knockdown of ARRDC3 on inflammasomeassociated pathways in human hepatocytes are shown in Figure 4. Most of inflammasome-associated genes were downregulated in HepG2 cells transfected with si-ARRDC3, compared with the si-control. However, among negative regulation molecules of inflammasomes, HSP90AA1 was significantly upregulated and B-cell CLL/lymphoma 2 (BCL2)-like 1 (BCL2L1), cathepsin B (CTSB), heat shock protein 90 $\mathrm{kDa}$ alpha, class B member 1 (HSP90AB) tended to be upregulated.

Effects of knockdown of ARRDC3 on Nucleotide-binding oligomerisation domain (NOD)like receptor-associated pathways and pro-inflammatory caspases in human hepatocytes are shown in Figure 5. Among NOD-like receptor-related molecules, NLR family, CARD domain containing 4 (NLRC4) and NLR family, pyrin domain containing 9 (NLRP9) tended to be downregulated, and NLR family member X1 (NLRX1) and NOD1 tended to be upregulated (Figure 5). Of interest, among Signaling downstream of NOD-like receptor-related molecules, Fas-associated via death domain (FADD), inhibitor of kappa light polypeptide gene enhancer in B-cells, kinase beta (IKBKB), inhibitor of kappa light polypeptide gene enhancer in B-cells, kinase gamma (IKBKG), Mitogen-activated protein kinase 1 (MAPK1), MAPK3, MAPK11, MAPK12, nuclear factor of kappa light polypeptide gene enhancer in B-cells 1 (NFKB1) and transforming growth factor (TGF)-beta activated kinase 1/MAP3K7 binding protein 1 (TAB1) tended to be upregulated (Figure 5b-5d). Two inflammatory caspases were significantly 
downregulated in HepG2 cells transfected with si-ARRDC3, compared with the si-control (Figure 5e).

In the present study, we demonstrated that free fatty acids induced ARRDC3 mRNA expression in hepatocytes and that upregulation of ARRDC3 in hepatocytes is associated with inhibition of hepatic stellate cell apoptosis, which may lead to the progression of liver fibrosis. We also demonstrated that ARRDC3 is strongly associated with inflammasome-associated gene expression. These results indicate that ARRDC3 plays a role in the progression of NAFLD and NASH.

A previous study [17] has shown that ARRDC3 deficiency in mice protects against obesity. ARRDC3 is a gene required for $\beta 2$-adrenergic receptor regulation and colocalizes with $\beta 2$-adrenergic receptors [41]. ARRDC3 also plays an important role in neural precursor development downregulated protein 4 (NEDD4)-mediated ubiquitination and endocytosis of activated $\beta 2$-adrenergic receptors and subsequent $\beta 2$-adrenergic receptor degradation [41]. Shi et al. [42] reported that abrogation of $\beta 2$-adrenergic receptors is known to modulate hepatic lipid accumulation and glucose tolerance in aging mice. Of interest, in the present study, we found an association between lipid accumulation and ARRDC3 expression in hepatocytes (Figure 1).

Two E3 ligases NEDD4 and NEDD4l, which are known to regulate membrane protein internalization and degradation via the endocytic pathway [43], are the proteins responsible for transmembrane $\mathrm{BAX}$ inhibitor motif-containing 1 (TMBIM1) ubiquitination [44]. TMBIM1 is an effective suppressor of steatohepatitis and a previously unknown regulator of the multivesicular body (MVB)-lysosomal pathway via targeting of the lysosomal degradation of TLR4 [44].

a

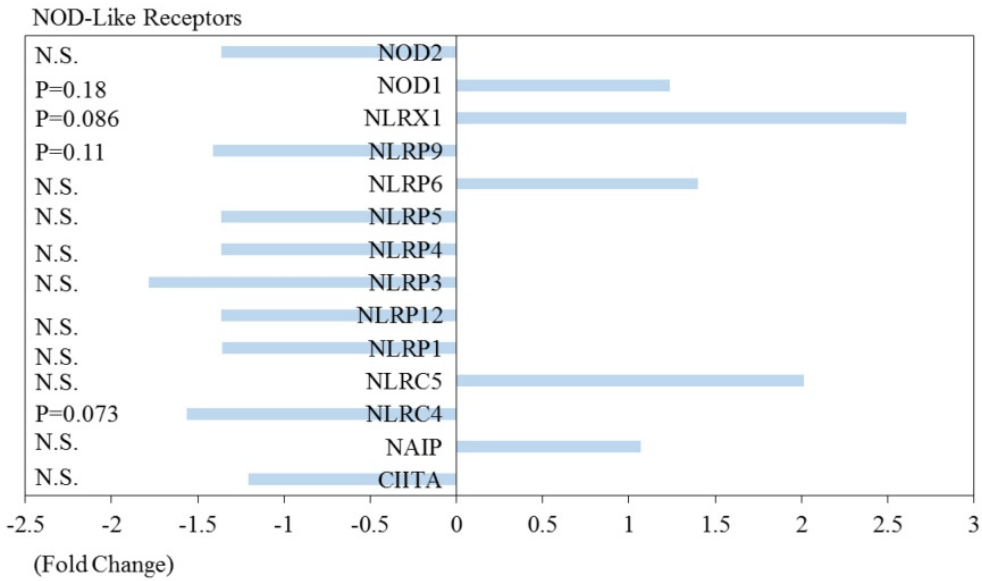

b

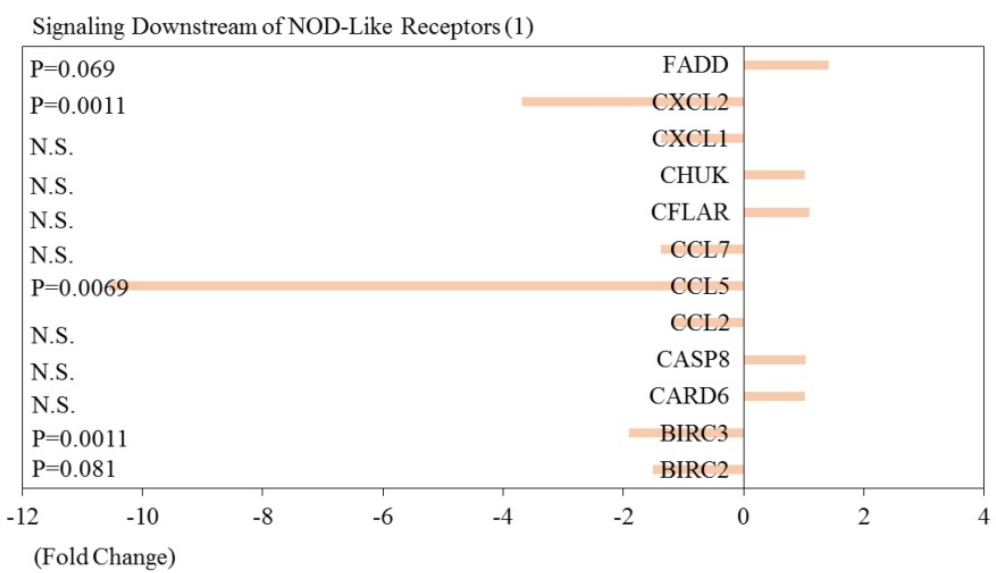




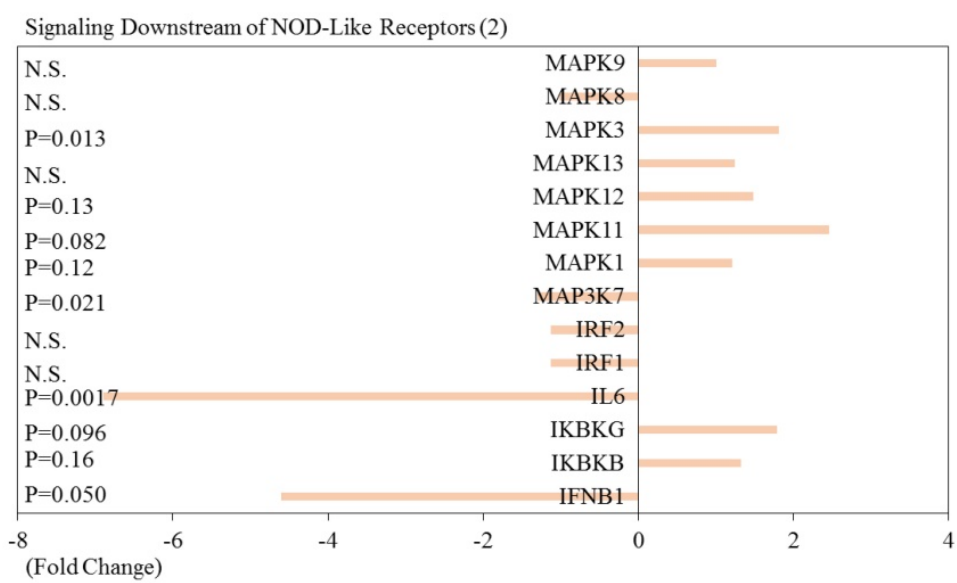

d

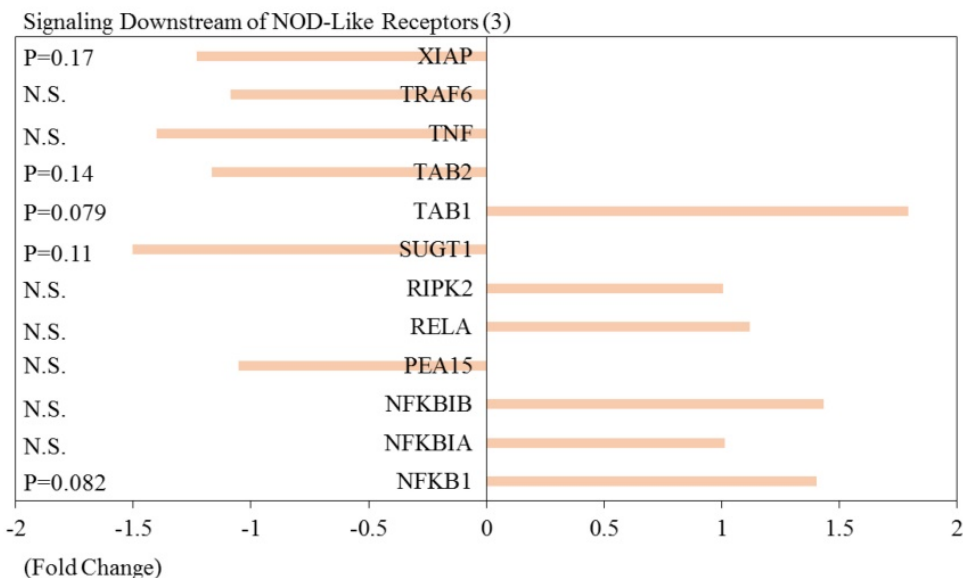

e

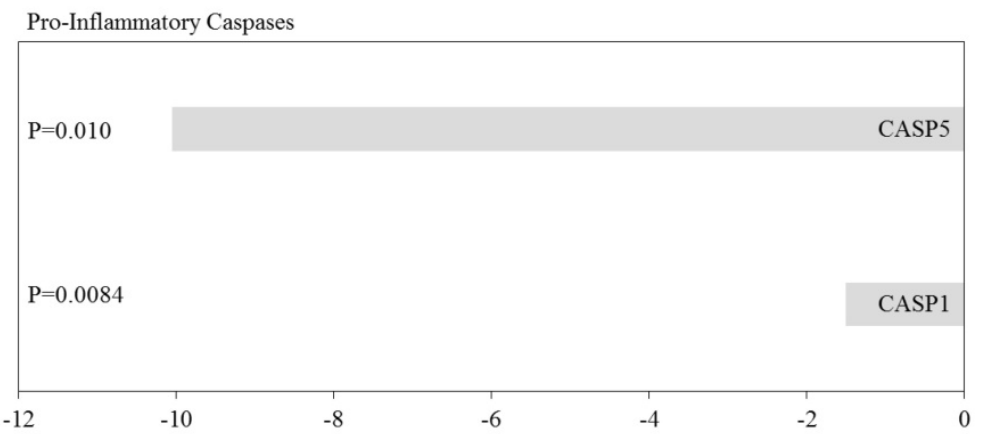

Figure 5. Effects of knockdown of endogenous arrestin domain-containing protein 3 (ARRDC3) on Nucleotide-binding oligomerisation domain (NOD)-like receptor-associated pathways and pro-inflammatory caspases in human HepG2 cells. Changes of gene expression in HepG2 cells transfected with si-ARRDC3, compared with si-control. (a) NOD-like receptors, (b), (c), (d) Signaling downstream of NOD-like receptors, (e) Pro-inflammatory caspases. P, p-values. N.S., not statistically significant difference.

We also observed that knockdown of ARRDC3 in human hepatocytes down-regulates inflammasome-associated gene expression (Table 1). It has been reported that activation of inflammasomes plays a role in the development of NAFLD and NASH
[27-40, 44]. The association between ARRDC3 and inflammasome-related pathways may have a role in the development of NAFLD and NASH. Further studies will be needed to clarify this point. 
Cell death is very important in the progression of NAFLD and NASH [4]. $\beta$-adrenergic receptor stimulation clearly induced the expression of v-raf-leukemia viral oncogene 1 (RAF-1) [45]. Inhibition of the pro-apoptotic function of ASK1 by RAF-1 may be the reason for maintaining survival [46]. Inhibition of the ASK1 pathway through the suppression of ARRDC3 may provide a novel mechanism in the management of NAFLD and NASH.

The number of patients with NAFLD and NAS has been increasing in the USA, Europe and Asian countries [3, 4]. NAFLD and NASH can lead to advanced liver diseases including cirrhosis and HCC [3]. Selonsertib which is a serine/threonine kinase inhibitor and targets ASK1 is now in phase III clinical trial for the treatment of NASH [47]. In phase II clinical trials of this drug, according to magnetic resonance (MR) elastography and biopsies at baseline and week $24,33 \%(18 / 54)$ had fibrosis improvement ( $\geq 1$-stage reduction) after undergoing 24 weeks of treatment with the study drug [48]. According to MR imaging-estimated proton density fat fraction and biopsies at baseline and week 24 , a $\geq 1$-grade reduction in steatosis was observed in $28 \%(18 / 65)$ [48]. A combination therapy of anti-inflammatory and anti-fibrotic intervention could be effective for NAFLD and NASH. ASK1 pathway plays a role in both inflammation and fibrosis of NAFLD and NASH $[4,49,50]$.

\section{Materials and Methods}

\section{Cell lines and reagents}

Human hepatoma cell lines (HepG2 and Huh7), hepatic stellate cell line LX-2 and human pancreatic cancer MIAPaCa-2 cells were maintained in Roswell Park Memorial Institute medium (RPMI 1640) (Sigma, St. Louis, MO, USA) supplemented with $1-10 \%$ fetal bovine serum, penicillin $(100 \mathrm{U} / \mathrm{mL})$ and streptomycin $(100 \mu \mathrm{g} / \mathrm{mL})$ at $5 \% \mathrm{CO} 2$ and $37^{\circ} \mathrm{C}$. HepG2, Huh7 and MIAPaCa-2 cells were purchased from the Japanese Collection of Research Bioresources Cell Bank (Ibaraki, Osaka, Japan) [26, 51]. LX-2 cells, spontaneously immortalized cells, were kindly provided by Prof. Scott L. Friedman, Mount Sinai Medical School, NY, USA [52]. Oleic acid-albumin from bovine serum was purchased from Sigma.

\section{Incubation of human hepatoma cell lines with oleic acids}

Before 24 hours of treatment with oleic acids, HepG2 and Huh7 cells were seeded in 6-well plates at a density of $0.5 \times 10^{6}$ cells/well. Cells were washed with PBS and incubated with or without $150 \mu \mathrm{M}$ or
$300 \mu \mathrm{M}$ oleic acids in RPMI with $10 \%$ fetal bovine serum for 24 hours.

RNA extraction, cDNA synthesis and real-time reverse transcription-PCR (RT-PCR)

Cellular RNA was isolated from cells by using the RNeasy Mini Kit (Qiagen, Tokyo, Japan). cDNA synthesis was performed by using PrimeScript RT reagent (Perfect Real Time) (Takara Bio, Otsu, Shiga, Japan) with random hexamers and oligo dT primers on GeneAmp PCR system 5700 (Applied Biosystems, Foster, CA, USA). PCR amplification was performed on cDNA templates using primers specific for ARRDC3 (sense primer [5'-ATCCCAGTGTGATGTG ACGA-3'] and antisense primer [5'-TTTGCAACAG AATCGGAAAA-3']) and for actin-beta (sense primer [5'-CAGCCATGTACGTTGCTATCCAGG-3']) and antisense primer [5'-AGGTCCAGACGCAGGATGG CATG-3']). For RNA quantification, real-time PCR was performed by using Power SYBR Green Master Mix (Thermo Fisher Scientific, Tokyo, Japan) with a 7500 Fast real-time PCR system (Applied Biosystems) as described previously [53]. The actin housekeeping gene was used for normalization, and data were analyzed by the comparative threshold cycle method. Relative quantification of gene expression using the $2-\Delta \Delta \mathrm{Ct}$ method correlated with absolute gene quantification obtained by standard curve [53]. Each real-time PCR assay was performed in triplicate.

\section{Transfection of small interfering RNA (siRNA)}

To transiently knockdown ARRDC3, approximately $0.5 \times 105$ cells were seeded in 35 mm-plates (Iwaki Glass, Tokyo, Japan) 24 hours prior to transfection. Cells were transfected with $50 \mathrm{nM}$ each of siRNA specific for ARRDC3 (si-ARRDC3) or control siRNA (si-control), using Effectene transfection reagent (Qiagen) according to the manufacturer's protocol [53]. After 48 hours of transfection, cellular RNA and conditioned medium were collected.

\section{Detection of apoptosis of $\mathbf{L X}-\mathbf{2}$ cells}

After 72 hours of incubation with conditioned media from HepG2 cells transfected with si-ARRDC3 or si-control, the APOPercentage apoptosis assay (Biocolor, Belfast, Northern Ireland) was used to evaluate apoptosis of LX-2 cells following the manufacturer's instruction. Transfer and exposure of phosphatidylserine to the exterior surface of the membrane have been linked to the onset of apoptosis. Phosphatidylserine transmembrane movement results in uptake of APOPercentage dye by apoptosis-committed cells. Purple-red stained cells were identified as apoptotic cells by light microscopy [26]. 


\section{Inflammasomes-associated signaling target PCR array}

HepG2 cells were transfected with $50 \mathrm{nM}$ each of si-ARRDC3 or si-control. After 48 hours of transfection, cellular RNA was extracted from both cells using the RNeasy Mini Kit (Qiagen). cDNA was synthesized with an RT2 First Strand cDNA Kit (Qiagen) according to the manufacturer's protocol. To examine the expression of 84 inflammasomeassociated genes, a human inflammasomes RT2 Prolifer PCR array (Qiagen) was performed with the SYBR Green real-time PCR-based method on 7500 Fast real-time PCR system (Applied Biosystems)[20]. The cycling program was as follows: $95^{\circ} \mathrm{C}$ for 10 minutes for 1 cycle, then 40 cycles of $95^{\circ} \mathrm{C}$ for 15 seconds and $60^{\circ} \mathrm{C}$ for 1 minute. Data were analyzed using RT2 Profiler PCR Array Data Analysis software (http://pcrdataanalysis.sabiosciences.com/pcr/array analysis.php). Gene expression was normalized to 5 internal control genes (beta-actin, beta-2-microglobulin, glyceraldehyde-3-phosphate dehydrogenase, hypoxantine phosphoribosyltransferase 1 and ribosomal protein, large, P0) to determine the fold change in gene expression by $2^{-\mathrm{ddCT}}$ (comparative cycle threshold) method.

\section{Statistical analysis}

All experiments were repeated at least three times independently, and all statistical analyses were performed using DA Stats software (O. Nagata, Nifty Serve: PAF01644). Statistical analyses were performed using a 2-tailed Student t-test or Welch t-test for paired data.

\section{Conclusion}

Recent studies demonstrated that ARRDC3 also play roles in human cancer signaling [54, 55]. We identified ARRDC3 as an important positive regulator in NAFLD and NASH. Targeting ARRDC3 may be a good strategy to develop a novel therapeutic method against NAFLD and NASH.

\section{Abbreviations}

NAFLD: Non-alcoholic fatty liver disease; NASH: Non-alcoholic steatohepatitis; ARRDC3: Arrestin domain-containing protein 3; AIM2: Absent in melanoma 2; BCL2: B-cell CLL/lymphoma 2; BCL2L1: BCL2-like 1; BIRC2: Baculoviral inhibitor of apoptosis (IAP) repeat containing 2; BIRC3: Baculoviral IAP repeat containing 3; CARD18: Caspase recruitment domain family, member 18; CARD6: Caspase recruitment domain family, member 6; CASP1: Caspase 1, apoptosis-related cysteine peptidase; CASP5: Caspase 5, apoptosis-related cysteine peptidase; CASP8: Caspase 8, apoptosis-related cysteine peptidase; CCL2: Chemokine (C-C motief) ligand 2; CCL5: Chemokine (C-C motief) ligand 5; CCL7: Chemokine (C-C motief) ligand 7; CD40LG: CD40 ligand; CFLAR: CASP8 and FADD-like apoptosis regulator; CHUK: Conserved helix-loop-helix ubiquitous kinase; CIITA: Class II, major histocompatibility complex, transactivator; CTSB: Cathepsin B; CXCL1: Chemokine (C-X-C motief) ligand 1; CXCL2: Chemokine (C-X-C motief) ligand 2; FADD: Fas-associated via death domain; HSP90AA1: Heat shock protein $90 \mathrm{kDa}$ alpha, class A member 1; HSP90AB1: Heat shock protein $90 \mathrm{kDa}$ alpha, class B member 1; HSP90B1: Heat shock protein $90 \mathrm{kDa}$ beta (Grp94), member 1; IFNB1: Interferon, beta 1, fibroblast; IFNG: Interferon, gamma; IKBKB: Inhibitor of kappa light polypeptide gene enhancer in B-cells, kinase beta; IKBKG: Inhibitor of kappa light polypeptide gene enhancer in B-cells, kinase gamma; IL12A: Interleukin 12A; IL12B: Interleukin 12B; IL18: Interleukin 18; IL1B: Interleukin 1, beta; IL33: Interleukin 33; IL6: Interleukin 6; IRAK1: Interleukin-1 receptor-associated kinase 1; IRF1: Interferon regulatory factor 1; IRF2: Interferon regulatory factor 2; MAP3K7: Mitogen-activated protein kinase kinase kinase 7; MAPK1: Mitogen-activated protein kinase 1; MAPK11: Mitogen-activated protein kinase 11; MAPK12: Mitogen-activated protein kinase 12; MAPK13: Mitogen-activated protein kinase 13; MAPK3: Mitogen-activated protein kinase 3; MAPK8: Mitogen-activated protein kinase 8; MAPK9: Mitogen-activated protein kinase 9; MEFV: Mediterranean fever; MYD88: Myeloid differentiation primary response gene (88); NAIP: NOD-like receptor (NLR) family, apoptosis inhibitory protein; NFKB1: Nuclear factor of kappa light polypeptide gene enhancer in B-cells 1; NFKB1A: Nuclear factor of kappa light polypeptide gene enhancer in B-cells inhibitor, alpha; NFKB1B: Nuclear factor of kappa light polypeptide gene enhancer in B-cells inhibitor, beta; NLRC4: NLR family, CARD domain containing 4; NLRC5: NLR family, CARD domain containing 5; NLRP1: NLR family, pyrin domain containing 1; NLRP12: NLR family, pyrin domain containing 12; NLRP3: NLR family, pyrin domain containing 3; NLRP4: NLR family, pyrin domain containing 4; NLRP5: NLR family, pyrin domain containing 5; NLRP6: NLR family, pyrin domain containing 6; NLRP9: NLR family, pyrin domain containing 9; NLRX1: NLR family member X1; NOD1: Nucleotide-binding oligomerization domain containing 1 ; NOD2: Nucleotide-binding oligomerization domain containing 2; P2RX7: Purinergic receptor P2X, ligand-gated ion channel, 7; PANX1: Pannexin 1; PEA15: Phosphoprotein enriched 
in astrocytes 15; PSTPIP1: Proline-serine-threonine phosphatase interacting protein 1; PTGS2: Prostaglandin-endoperoxide synthase 2; PYCARD: PYD and CARD domain containing; PYDC1: PYD (pyrin domain) containing 1; MOK: Renal tumor antigen; RELA: V-rel reticuloendotheliosis viral oncogene homolog A (avian); RIPK2: Receptor-interacting serine-threonine kinase 2; SUGT1: SGT1, suppressor of G2 allele of SKP1 (S. cerevisiae); TAB1: TGF-beta activated kinase1/MAP3K7 binding protein 1; TAB2: TGF-beta activated kinase1/MAP3K7 binding protein 2; TIRAP: Toll-interleukin 1 receptor (TIR) domain containing adaptor protein; TNF: Tumor necrosis factor; TNFSF11: Tumor necrosis factor (ligand) superfamily, member 11; TNFSF14: Tumor necrosis factor (ligand) superfamily, member 14; TNFSF4: Tumor necrosis factor (ligand) superfamily, member 4; TRAF6: TNF receptor-associated factor 6; TXNIP: Thioredoxin interacting protein; XIAP: X-linked inhibitor of apoptosis.

\section{Acknowledgements}

The authors thanks to Prof. Scott L. Friedman, Mount Sinai Medical School, NY, USA for providing us LX-2 cells.

\section{Funding}

This work was supported by JSPS KAKENHI GRANT Number JP17K09404 (to T.K.).

\section{Competing Interests}

Tatsuo Kanda and Mitsuhiko Moriyama received research grants from AbbVie, Eisai, Daiichi-Sankyo, Shionogi, Mitsubishi-Tanabe Pharma, Astellas, Ono Pharma and Takeda Pharma. The other authors declare no conflict of interest. The funders had no role in the design of the study; in the collection, analyses, or interpretation of data; in the writing of the manuscript, or in the decision to publish the results.

\section{References}

1. Younossi Z, Stepanova M, Ong JP, et al. Nonalcoholic steatohepatitis is the fastest growing cause of hepatocellular carcinoma in liver transplant candidates. Clin Gastroenterol Hepatol. 2019; 17: 748-55. DOI: 10.1016/j.cgh.2018.05.057. PMID: 29908364.

2. Tateishi R, Okanoue T, Fujiwara N, et al. Clinical characteristics, treatment, and prognosis of non- $\mathrm{B}$, non- $\mathrm{C}$ hepatocellular carcinoma: a large retrospective multicenter cohort study. J Gastroenterol. 2015; 50: 350-60. DOI: 10.1007/s00535-014-0973-8. PMID: 24929638.

3. Estes C, Anstee QM, Arias-Loste MT, et al. Modeling NAFLD Disease Burden in China, France, Germany, Italy, Japan, Spain, United Kingdom, and United States for the period 2016-2030. J Hepatol. 2018; 69: 896-904. DOI: 10.1016/j.jhep.2018.05.036. PMID: 29886156.

4. Kanda T, Matsuoka S, Yamazaki M, et al. Apoptosis and non-alcoholic fatty liver diseases. World J Gastroenterol. 2018; 24: 2661-72. DOI: 10.3748/wjg.v24.i25.2661. PMID: 29991872.

5. Lefkowitz RJ, Rajagopal K, Whalen EJ. New roles for beta-arrestins in cell signaling: not just for seven-transmembrane receptors. Mol Cell. 2006; 24: 643-52. DOI: 10.1016/j.molcel.2006.11.007. PMID: 17157248.
6. Luan B, Zhao J, Wu H, et al. Deficiency of a beta-arrestin-2 signal complex contributes to insulin resistance. Nature. 2009; 457: 1146-9. DOI: 10.1038/nature07617. PMID: 19122674.

7. Rojanathammanee L, Harmon EB, Grisanti LA, et al. The 27-kDa heat shock protein confers cytoprotective effects through a beta 2-adrenergic receptor agonist-initiated complex with beta-arrestin. Mol Pharmacol. 2009; 75: 855-65. DOI: 10.1124/mol.108.053397. PMID: 19176359.

8. Xu TR, Baillie GS, Bhari N, et al. Mutations of beta-arrestin 2 that limit self-association also interfere with interactions with the beta2-adrenoceptor and the ERK1/2 MAPKs: implications for beta2-adrenoceptor signalling via the ERK1/2 MAPKs. Biochem J. 2008; 413: 51-60. DOI: 10.1042/BJ20080685. PMID: 18435604.

9. Boularan $\mathrm{C}$, Scott MG, Bourougaa $\mathrm{K}$, et al. beta-arrestin 2 oligomerization controls the Mdm2-dependent inhibition of p53. Proc Natl Acad Sci USA. 2007; 104: 18061-6. DOI: 10.1073/pnas.0705550104. PMID: 17984062.

10. Fuster G, Busquets S, Ametller E, et al. Are peroxisome proliferator-activated receptors involved in skeletal muscle wasting during experimental cancer cachexia? Role of beta2-adrenergic agonists. Cancer Res. 2007; 67: 6512-9. DOI: 10.1158/0008-5472.CAN-07-0231. PMID: 17616713

11. Berthouze-Duquesnes M, Lucas A, Saulière A, et al. Specific interactions between Epac1, $\beta$-arrestin2 and PDE4D5 regulate $\beta$-adrenergic receptor subtype differential effects on cardiac hypertrophic signaling. Cell Signal. 2013; 25: 970-80. DOI: 10.1016/j.cellsig.2012.12.007. PMID: 23266473.

12. Szepietowska B, Zhu W, Sherwin RS. 32 -Adrenergic receptor agonist administration promotes counter-regulatory responses and recovery from hypoglycaemia in rats. Diabetologia. 2013; 56: 2517-23. DOI: 10.1007/s00125-013-3009-7. PMID: 23933834.

13. Breitman M, Kook S, Gimenez LE, et al. Silent scaffolds: inhibition OF c-Jun $\mathrm{N}$-terminal kinase 3 activity in cell by dominant-negative arrestin-3 mutant. J Biol Chem. 2012; 287: 19653-64. DOI: 10.1074/jbc.M112.358192. PMID: 22523077.

14. Zhang P, Wang PX, Zhao LP, et al. The deubiquitinating enzyme TNFAIP3 mediates inactivation of hepatic ASK1 and ameliorates nonalcoholic steatohepatitis. Nat Med. 2018; 24: 84-94. DOI: 10.1038/nm.4453. PMID: 29227477.

15. Kang DS, Tian $X$, Benovic JL. Role of $\beta$-arrestins and arrestin domain-containing proteins in $\mathrm{G}$ protein-coupled receptor trafficking. Curr Opin Cell Biol. 2014; 27: 63-71. DOI: 10.1016/j.ceb.2013.11.005. PMID: 24680432.

16. Patwari P, Lee RT. An expanded family of arrestins regulate metabolism. Trends Endocrinol Metab. 2012; 23: 216-22. DOI: 10.1016/j.tem.2012.03.003. PMID: 22520962.

17. Patwari P, Emilsson V, Schadt EE, et al. The arrestin domain-containing 3 protein regulates body mass and energy expenditure. Cell Metab. 2011; 14: 671-83. DOI: 10.1016/j.cmet.2011.08.011. PMID: 21982743.

18. Rafiq S, Tapper W, Collins A, et al. Identification of inherited genetic variations influencing prognosis in early-onset breast cancer. Cancer Res. 2013; 73: 1883-91. DOI: 10.1158/0008-5472.CAN-12-3377. PMID: 23319801.

19. Cai Q, Zhang B, Sung H, et al. Genome-wide association analysis in East Asians identifies breast cancer susceptibility loci at 1q32.1, 5q14.3 and 15q26.1. Nat Genet. 2014; 46: 886-90. DOI: 10.1038/ng.3041. PMID: 25038754.

20. Higuchi T, Moriyama M, Fukushima A, et al. Association of mRNA expression of iron metabolism-associated genes and progression of non-alcoholic steatohepatitis in rats. Oncotarget. 2018; 9: 26183-94. DOI: 10.18632/oncotarget.25488. PMID: 29899851.

21. Wang D, Yang PN, Chen J, et al. Promoter hypermethylation may be an important mechanism of the transcriptional inactivation of ARRDC3, GATA5, and ELP3 in invasive ductal breast carcinoma. Mol Cell Biochem. 2014; 396: 67-77. DOI: 10.1007/s11010-014-2143-y. PMID: 25148870.

22. Hoque R, Farooq A, Ghani A, et al. Lactate reduces liver and pancreatic injury in Toll-like receptor- and inflammasome-mediated inflammation via GPR81-mediated suppression of innate immunity. Gastroenterology. 2014; 146: 1763-74. DOI: 10.1053/j.gastro.2014.03.014. PMID: 24657625.

23. Moravcová A, Červinková Z, Kučera $\mathrm{O}$, et al. The effect of oleic and palmitic acid on induction of steatosis and cytotoxicity on rat hepatocytes in primary culture. Physiol Res. 2015; 64 Suppl 5: S627-36. PMID: 26674288.

24. Ricchi M, Odoardi MR, Carulli L, et al. Differential effect of oleic and palmitic acid on lipid accumulation and apoptosis in cultured hepatocytes. J Gastroenterol Hepatol. 2009; 24: 830-40. DOI: 10.1111/j.1440-1746.2008.05733.x. PMID: 19207680

25. Nwe Win $N$, Kanda $T$, Nakamura $M$, et al. Free fatty acids or high-concentration glucose enhances hepatitis A virus replication in association with a reduction in glucose-regulated protein 78 expression. Biochem Biophys Res Commun. 2017; 483: 694-9. DOI: 10.1016/j.bbrc.2016.12.080. PMID: 27986562.

26. Sasaki R, Kanda T, Nakamura M, et al. Possible Involvement of Hepatitis B Virus Infection of Hepatocytes in the Attenuation of Apoptosis in Hepatic Stellate Cells. PLoS One 2016; 11: e0146314. DOI: 10.1371/journal.pone.0146314. PMID: 26731332

27. Dai $W$, Wang $K$, Zheng $X$, et al. High fat plus high cholesterol diet lead to hepatic steatosis in zebrafish larvae: a novel model for screening anti-hepatic steatosis drugs. Nutr Metab. (Lond.) 2015; 12: 42. DOI: 10.1186/s12986-015-0036-z. PMID: 26583037.

28. Sookoian S, Gianotti TF, Rosselli MS, et al. Liver transcriptional profile of atherosclerosis-related genes in human nonalcoholic fatty liver disease. 
Atherosclerosis. 2011; 218: 378-85. DOI: 10.1016/j.atherosclerosis.2011.05.014. PMID: 21664615

29. Morrison MC, Liang W, Mulder P, et al. Mirtoselect, an anthocyanin-rich bilberry extract, attenuates non-alcoholic steatohepatitis and associated fibrosis in $\mathrm{ApoE}(*) 3$ Leiden mice. J Hepatol. 2015; 62: 1180-6. DOI: 10.1016/j.jhep.2014.12.011. PMID: 25514555.

30. Min HK, Mirshahi F, Verdianelli A, et al. Activation of the GP130-STAT3 axis and its potential implications in nonalcoholic fatty liver disease. Am J Physiol Gastrointest Liver Physiol. 2015; 308: G794-803. DOI: 10.1152/ajpgi.00390.2014. PMID: 25747354.

31. Li BH, He FP, Yang X, et al. Steatosis induced CCL5 contributes to early-stage liver fibrosis in nonalcoholic fatty liver disease progress. Transl Res. 2017; 180: 103-17.e4 DOI: 10.1016/j.trsl.2016.08.006. PMID: 27639593.

32. Mridha AR, Wree A, Robertson AAB, et al. NLRP3 inflammasome blockade reduces liver inflammation and fibrosis in experimental NASH in mice. J Hepatol. 2017; 66: 1037-46. DOI: 10.1016/j.jhep.2017.01.022. PMID: 28167322.

33. Zhu Q, Lin L, Cheng Q, et al. The role of acid sphingomyelinase and caspase 5 in hypoxia-induced HuR cleavage and subsequent apoptosis in hepatocytes. Biochim Biophys Acta. 2012; 1821: 1453-61. DOI: 10.1016/j.bbalip.2012.08.005. PMID: 22906436.

34. Zhang X, Zhang JH, Chen XY, et al. Reactive oxygen species-induced TXNIP drives fructose-mediated hepatic inflammation and lipid accumulation through NLRP3 inflammasome activation. Antioxid Redox Signal. 2015; 22: 848-70. DOI: 10.1089/ars.2014.5868. PMID: 25602171.

35. Zhang Y, O'Keefe RJ, Jonason JH. BMP-TAK1 (MAP3K7) Induces Adipocyte Differentiation Through PPARY Signaling. J Cell Biochem. 2017; 118: 204-10. DOI: 10.1002/jcb.25626. PMID: 27293199.

36. Xiao F, Waldrop SL, Bronk SF, et al. Lipoapoptosis induced by saturated free fatty acids stimulates monocyte migration: a novel role for Pannexin1 in liver cells. Purinergic Signal. 2015; 11: 347-59. DOI: 10.1007/s11302-015-9456-5. PMID: 26054298.

37. Yang MR, Zhang $\mathrm{Y}, \mathrm{Wu} \mathrm{XX}$, Chen $\mathrm{W}$. Critical genes of hepatocellular carcinoma revealed by network and module analysis of RNA-seq data. Eur Rev Med Pharmacol Sci. 2016; 20: 4248-56. PMID: 27831650.

38. Marcolin E, San-Miguel B, Vallejo D, et al. Quercetin treatment ameliorates inflammation and fibrosis in mice with nonalcoholic steatohepatitis. J Nutr. 2012; 142: 1821-8. DOI: 10.3945/jn.112.165274. PMID: 22915297.

39. Yang L, Miura K, Zhang B, et al. TRIF Differentially Regulates Hepatic Steatosis and Inflammation/Fibrosis in Mice. Cell Mol. Gastroenterol. Hepatol. 2017, 3, 469-83. DOI: 10.1016/j.jcmgh.2016.12.004. PMID: 28462384.

40. Csak T, Dolganiuc A, Kodys $\mathrm{K}$, et al. Mitochondrial antiviral signaling protein defect links impaired antiviral response and liver injury in steatohepatitis in mice. Hepatology. 2011; 53: 1917-31. DOI: 10.1002/hep.24301. PMID: 21425308

41. Nabhan JF, Pan H, Lu Q. Arrestin domain-containing protein 3 recruits the NEDD4 E3 ligase to mediate ubiquitination of the beta2-adrenergic receptor. EMBO Rep. 2010; 11: 605-11. DOI: 10.1038/embor.2010.80. PMID: 20559325.

42. Shi $Y$, Shu $Z$ I, Xue $X$ et al, $\beta 2$-Adrenergic receptor ablation modulates hepatic lipid accumulation and glucose tolerance in aging mice. Exp Gerontol. 2016; 78: 32-8. DOI: 10.1016/j.exger.2016.03.005. PMID: 26952573.

43. Rotin D, Kumar S. Physiological functions of the HECT family of ubiquitin ligases. Nat Rev Mol Cell Biol. 2009; 10: 398-409. DOI: 10.1038/nrm2690. PMID: 19436320

44. Zhao GN, Zhang P, Gong J, et al. Tmbim1 is a multivesicular body regulator that protects against non-alcoholic fatty liver disease in mice and monkeys by targeting the lysosomal degradation of Tlr4. Nat Med. 2017; 23: 742-52. DOI: 10.1038/nm.4334. PMID: 28481357.

45. Safi SZ, Qvist R, Ong G, et al. Stimulation of $\beta$-adrenergic receptors plays a protective role via increased expression of RAF-1 and PDX-1 in hyperglycemic rat pancreatic islet (RIN-m5F) cells. Arch Med Sci. 2017; 13: 470-80. DOI: 10.5114/aoms.2016.64131. PMID: 28261303.

46. Chen J, Fujii K, Zhang L, et al. Raf-1 promotes cell survival by antagonizing apoptosis signal-regulating kinase 1 through a MEK-ERK independent mechanism. Proc Natl Acad Sci USA. 2001; 98: 7783-8. DOI: 10.1073/pnas.141224398. PMID: 11427728.

47. Ji N, Yang Y, Cai CY, et al. Selonsertib (GS-4997), an ASK1 inhibitor, antagonizes multidrug resistance in ABCB1- and ABCG2-overexpressing cancer cells. Cancer Lett. 2019; 440-441: 82-93. DOI: 10.1016/j.canlet.2018.10.007. PMID: 30315846.

48. Jayakumar S, Middleton MS, Lawitz EJ, et al. Longitudinal correlations between MRE, MRI-PDFF, and liver histology in patients with non-alcoholic steatohepatitis: Analysis of data from a phase II trial of selonsertib. J Hepatol. 2019; 70: 133-41. DOI: 10.1016/j.jhep.2018.09.024. PMID: 30291868.

49. Tacke F, Weiskirchen R. An update on the recent advances in antifibrotic therapy. Expert Rev Gastroenterol Hepatol. 2018; 12: 1143-52. DOI: 10.1080/17474124.2018.1530110. PMID: 30261763

50. Sumida Y, Yoneda M. Current and future pharmacological therapies for NAFLD/NASH. J Gastroenterol. 2018; 53: 362-76. DOI: 10.1007/s00535-017-1415-1. PMID: 29247356.

51. Sasaki R, Kanda T, Wu S, et al. Association between hepatitis B virus and MHC class I polypeptide-related chain A in human hepatocytes derived from human-mouse chimeric mouse liver. Biochem Biophys Res Commun. 2015; 464: 1192-5. DOI: 10.1016/j.bbrc.2015.07.102. PMID: 26212443.
52. $\mathrm{Xu} \mathrm{L}$, Hui AY, Albanis $\mathrm{E}$, et al. Human hepatic stellate cell lines, LX-1 and LX-2: new tools for analysis of hepatic fibrosis. Gut 2005; 54: 142-51. DOI: 10.1136/gut.2004.042127. PMID: 15591520.

53. Wu S, Kanda T, Imazeki F, et al. Hepatitis B virus e antigen downregulates cytokine production in human hepatoma cell lines. Viral Immunol. 2010; 23: 467-76. DOI: 10.1089/vim.2010.0042. PMID: 20883161.

54. Arakaki AKS, Pan WA, Trejo J. GPCRs in Cancer: Protease-Activated Receptors, Endocytic Adaptors and Signaling. Int J Mol Sci. 2018; 19. DOI: 10.3390/ijms19071886. PMID: 29954076.

55. Takeuchi F, Kukimoto I, Li Z, et al. Genome-wide association study of cervical cancer suggests a role for ARRDC3 gene in human papillomavirus infection. Hum Mol Genet. 2019: 28; 341-8. DOI: 10.1093/hmg/ddy390. PMID: 30412241 